\title{
Influence of Diabetes Mellitus on the Endovascular Treatment of Abdominal Aortic Aneurysms
}

\author{
Lina J. Leurs, MSc; Robert J.F. Laheij, PhD; Jacob Buth, MD on behalf of the \\ EUROSTAR Collaborators
}

EUROSTAR Data Registry Centre, Department of Vascular Surgery, Catharina Hospital, Eindhoven, The Netherlands.

\begin{abstract}
$\checkmark$
Purpose: To investigate the influence of diabetes mellitus on outcome after endovascular abdominal aortic aneurysm (AAA) repair.

Methods: Of 6017 patients enrolled in the EUROSTAR registry after undergoing endovascular AAA repair between May 1994 and December 2003, 731 (12\%) had diabetes mellitus (690 men; mean age 72 years, range 37-100). Patient demographics, risk factors, aneurysm morphology, operative and procedural details, complications, major events, and regular follow-up information were compared. The relationships of complications and events to diabetes mellitus, which were tested with multivariate logistic regression analysis and Cox proportional hazards modeling, are expressed as odds ratios (OR) and hazard rates (HR) with $95 \%$ confidence intervals (CI). Survival was compared with life-table analysis.

Results: A significantly higher risk of device-related complications was observed in diabetic patients ( $8 \%$ versus $6 \%, \mathrm{p}<0.049$; OR $1.35,95 \% \mathrm{Cl} 1.00$ to 1.82 ). The greatest difference in the groups was in mortality, which was significantly higher in the diabetic population (13\%) compared to the nondiabetic patients (10\%, p<0.039; OR 1.27, 95\% Cl 1.01 to 1.59). Deaths, which occurred at a higher frequency within the 30-day perioperative period in diabetic patients, were primary due to cardiac complications. Insulin-controlled type 2 diabetic patients had significantly lower rates of early and late endoleaks and secondary interventions than diet-controlled type 2 diabetics $(p=0.002, p=0.0001$, and $p=0.0008$, respectively) and nondiabetic patients $(p=0.002, p=0.0005$, and $p=0.0025$, respectively). The cumulative survival after 48 months did not differ significantly: $74 \%$ in diabetics and $79 \%$ in the population without diabetes.

Conclusions: Patients with diabetes mellitus had a significantly higher early mortality rate after EVAR, but their long-term survival was similar to nondiabetic patients.
\end{abstract}

J Endovasc Ther 2005;12:288-296

Key words: diabetes, abdominal aortic aneurysm, endovascular repair, outcome analysis, mortality, complications, endoleak

Endovascular aneurysm repair (EVAR) has become increasingly common for the treatment of abdominal aortic aneurysm (AAA). This minimally invasive approach is of particular benefit to patients with coexistent diseases who would be at high risk for conventional surgery. ${ }^{1,2}$ Early and midterm success of en- dovascular AAA treatment has been documented extensively in a number of articles. ${ }^{3-6}$ Recently, the early benefits versus open surgery (lower 30-day morbidity/mortality and reduced hospital stay) were confirmed in two randomized clinical trials. ${ }^{7,8}$

Diabetes mellitus has not been widely as-

The authors have no commercial, proprietary, or financial interest in the products or companies described in this article.

Address for correspondence and reprints: LJ Leurs, Department of Vascular Surgery, Catharina Hospital, PO Box 1350, 5602 ZA Eindhoven, The Netherlands. Fax: 31-40-244-3370; E-mail: EUROSTAR@iae.nl 
sessed as a comorbid factor that might impact the risk or outcome of EVAR. Diabetes is associated with accelerated rates of mortality, particularly from cardiovascular causes, and several chronic diseases, such as renal and peripheral occlusive diseases. ${ }^{9}$ These comorbidities may increase the risk of open aneurysm repair, so it may be advantageous for diabetic patients with AAA to undergo EVAR. In this report, we investigate if patients with diabetes mellitus had different EVAR outcome than nondiabetics.

\section{METHODS}

\section{Study Design}

In July 1996, the EUROSTAR project was established with the objective of collecting and analyzing various aspects of endovascular AAA treatment. Data from patients operated before the start of the registry were retrieved retrospectively from hospital notes and patient records. Patient demographics, risk factors, aneurysm morphology, operative and procedural details, incidence of complications and major events (death, rupture, and conversion to open repair), and regular follow-up information were collected on standardized EUROSTAR Case Record Forms. The American Society of Anesthesiologists (ASA) risk classification and the Society for Vascular Surgery (SVS) risk score ${ }^{10}$ were used to represent the patient risk profile. In the latter, risk scores of 1 and 2 indicated diet-controlled (oral hypoglycemic agent) or insulin-controlled type 2 diabetes, respectively; type 1 diabetes was indicated by a risk score of 3 .

Intraoperative complications encompassed device-related sequelae, procedural failure, and arterial complications. Postoperative (inhospital) complications were grouped into systemic, procedure- and device-related, and access site/lower limb. Endoleaks discovered at the completion angiogram were also included in the 30-day complication assessment. Late complications included endoleaks, kinking, thrombosis, and migration occurring after 30 days. Follow-up examinations were performed at 1, 3, 6, 12, 18, and 24 months and yearly thereafter. ${ }^{15}$

\section{Patient Population}

Between May 1994 and December 2003, 6017 patients underwent endovascular AAA repair in 163 European centers (Appendix). Of these, 731 patients (690 men; mean age 72 years, range 37-100) had diabetes mellitus: 21 patients with type 1,505 with diet-controlled type 2, and 205 with insulin-controlled type 2.

\section{Data Analysis}

Data were recorded on a computerized database. Odds ratios (OR) with 95\% confidence intervals $(\mathrm{Cl})$ were calculated for time-independent variables with multivariate logistic regression analysis, while hazard rates (HR) were calculated using the Cox proportional hazards model for time-dependent characteristics. Both tests were used to test associations between complications and diabetes. The models were adjusted for patient age, sex, ASA classification, SVS risk factors, obesity, and unfitness for traditional open surgery or general anesthesia. In the Cox proportional hazard model for follow-up events, the immediate failures, patients lost to follow-up, and event-free observations were censored. Analyses were first performed for diabetic versus nondiabetic patients, and then the type 2 diabetic population was categorized as diet-controlled (oral hypoglycemic agent) versus insulin-controlled patients. Life-table analyses and Kaplan-Meier survival estimates were used to analyze survival. Statistical significance was set at $p<0.05$. Data analyses were performed with SAS statistical software (version 8.0; SAS Institutes, Cary, NC, USA).

\section{RESULTS}

The diabetic population had significantly higher proportions of several risk factors (Table 1), including hypertension $(76 \%$ versus $61 \%$ ), hyperlipemia ( $25 \%$ versus $15 \%$ ), impaired cardiac function ( $41 \%$ versus $30 \%$ ), carotid disease $(11 \%$ versus $5 \%)$, renal disease $(33 \%$ versus $17 \%)$, poor pulmonary status (25\% versus $18 \%$ ), and obesity (39\% versus $24 \%$ ). Owing to the greater preponderance of ASA class $\geq 3$ risk $(p<0.0001)$, diabetic patients were considered significantly more un- 


\begin{tabular}{|c|c|c|c|c|}
\hline & \multicolumn{2}{|c|}{$\begin{array}{c}\text { TABLE } 1 \\
\text { Patient Demographics }\end{array}$} & & \\
\hline & \multicolumn{2}{|c|}{$\begin{array}{c}\text { Diabetics } \\
n=731\end{array}$} & \multicolumn{2}{|c|}{$\begin{array}{c}\text { Nondiabetics } \\
n=5286\end{array}$} \\
\hline & 690 & $(94.39 \%)$ & 4933 & $(93.32 \%)$ \\
\hline Mean age, y (range) & 71.9 & $(37-100)$ & 71.7 & $(28-100)$ \\
\hline Age $>70$ y & 451 & $(61.70 \%)$ & 3213 & $(60.82 \%)$ \\
\hline ASA $3 *$ & 493 & $(67.44 \%)$ & 2640 & $(49.94 \%)$ \\
\hline \multicolumn{5}{|l|}{ SVS risk } \\
\hline Smoking & 196 & $(26.81 \%)$ & 1286 & $(24.33 \%)$ \\
\hline Hypertension* & 555 & (75.92\%) & 3208 & $(60.69 \%)$ \\
\hline Hyperlipemia* & 183 & $(25.03 \%)$ & 814 & $(15.40 \%)$ \\
\hline Cardiac status* & 299 & $(40.90 \%)$ & 1560 & $(29.51 \%)$ \\
\hline Carotid disease* & 79 & $(10.81 \%)$ & 268 & $(5.07 \%)$ \\
\hline Renal status* & 238 & $(32.56 \%)$ & 889 & $(16.82 \%)$ \\
\hline Pulmonary status* & 183 & $(25.03 \%)$ & 976 & $(18.46 \%)$ \\
\hline \multicolumn{5}{|l|}{ Indication for EVAR } \\
\hline Previous laparotomy* & 243 & $(33.24 \%)$ & 1414 & $(26.79 \%)$ \\
\hline Obesity* & 286 & (39.12\%) & 1240 & $(23.50 \%)$ \\
\hline Unfit for open procedure* & 222 & $(30.37 \%)$ & 1111 & $(21.07 \%)$ \\
\hline Unfit for general anesthesia* & 100 & $(13.74 \%)$ & 360 & $(6.83 \%)$ \\
\hline Max AAA diameter $>60 \mathrm{~mm}$ & 224 & (31.33\%) & 1488 & $(28.81 \%)$ \\
\hline
\end{tabular}

ASA: American Society of Anesthesiologists, SVS: Society for Vascular Surgery.

* Significant difference between diabetic and nondiabetic patients $(p<0.0001)$.

fit for open surgery and general anesthesia $(\mathrm{p}<0.0001)$.

Device-related complications appeared significantly more often in diabetic patients $(8 \%$ versus $6 \%, p<0.049$ ) than in nondiabetics (OR $1.35,95 \% \mathrm{Cl} 1.00$ to 1.82 ) (Table 2). Arterial complications, in particular, occlusion of the renal artery, occurred more frequently in patients with diabetes $(1.1 \%$ versus $0.3 \%$, $\mathrm{p}<0.010$; OR $3.21,95 \% \mathrm{Cl} 1.31$ to 7.84$)$. The 30 -day mortality rate in the diabetic group $(4 \%)$ was significantly higher than in the nondiabetic patients $(2 \%, \mathrm{p}<0.024$; OR $1.67,95 \%$ $\mathrm{Cl} 1.07$ to 2.61). There was no difference in early conversion or rupture rates. The higher mortality in the diabetic population was caused predominantly by cardiac complications (Table 3). Additional analyses of type 2 diabetics (Table 4) demonstrated a significantly lower proportion of early endoleaks in insulin-controlled (8\%) compared to diet-controlled patients $(17 \%, \mathrm{p}<0.0023)$ and the nondiabetic $(16 \%, p<0.0021)$ cohort.

Over a mean follow-up of $19.36 \pm 18.88$ months (range 0-96), 59 patients were lost to follow-up (51 [1.0\%] nondiabetics and 8 [1.1\%] in the diabetic subgroup). Follow-up was complete in $70 \%$ of the population (Table 5). Different types of endoleaks occurred in similar proportions in diabetic and nondiabetic patients, as did kinking, stenosis, thrombosis, and migration. Late death occurred at comparable rates (both 9\%). However, overall mortality was significantly higher in the diabetic population (13\%) compared to the nondiabetic patients ( $10 \%, p<0.039$; OR $1.27,95 \%$ $\mathrm{Cl} 1.01$ to 1.59 ). No differences were found between the groups in late conversion or rupture rates. The cumulative survival rates after 48 months did not differ significantly: $74 \%$ in diabetics and $79 \%$ in the population without diabetes (Figure).

Further analysis of type 2 diabetic patients (Table 6) revealed that insulin-controlled patients had significantly fewer endoleaks $(8 \%$ versus $20 \%[p=0.0001]$ and $18 \%[p=0.0005])$ and secondary interventions ( $4 \%$ versus $12 \%$ [ $p=0.0008]$ and $11 \%[p=0.0025])$ compared to diet-controlled and nondiabetic patients, respectively.

\section{DISCUSSION}

Diabetes mellitus is part of a complex of risk factors for cardiovascular disease that features 


\begin{tabular}{|c|c|c|c|c|}
\hline \multicolumn{5}{|c|}{$\begin{array}{c}\text { TABLE } 2 \\
\text { Early (30-Day) Complications }\end{array}$} \\
\hline & $\begin{array}{c}\text { Diabetic } \\
\text { Patients } \\
n=731\end{array}$ & $\begin{array}{c}\text { Nondiabetic } \\
\text { Patients } \\
n=5286\end{array}$ & $\begin{array}{l}\text { Adjusted } \\
\text { Odds Ratio }\end{array}$ & $95 \% \mathrm{Cl}$ \\
\hline \multicolumn{5}{|l|}{ Intraoperative } \\
\hline $\begin{array}{l}\text { Device-related* } \\
\text { Failed procedure } \\
\text { Arterial } \\
\text { Thrombus/emboli } \\
\text { Occluded renal artery* }\end{array}$ & $\begin{array}{r}58(7.96 \%) \\
17(2.33 \%) \\
36(4.94 \%) \\
2(0.38 \%) \\
8(1.10 \%)\end{array}$ & $\begin{array}{r}338(6.41 \%) \\
90(1.71 \%) \\
201(3.81 \%) \\
36(0.68 \%) \\
16(0.30 \%)\end{array}$ & $\begin{array}{l}1.35 \\
1.37 \\
1.27 \\
0.62 \\
3.21\end{array}$ & $\begin{array}{l}1.00 \text { to } 1.82 \\
0.79 \text { to } 2.35 \\
0.87 \text { to } 1.85 \\
0.19 \text { to } 2.08 \\
1.31 \text { to } 7.84\end{array}$ \\
\hline \multicolumn{5}{|l|}{ In-Hospital } \\
\hline $\begin{array}{l}\text { Systemic } \\
\text { Procedure/device-related } \\
\text { Access/lower limb }\end{array}$ & $\begin{array}{l}91(12.48 \%) \\
26(3.57 \%) \\
62(8.50 \%)\end{array}$ & $\begin{array}{l}681(12.92 \%) \\
138(2.62 \%) \\
378(7.17 \%)\end{array}$ & $\begin{array}{l}0.85 \\
1.46 \\
1.19\end{array}$ & $\begin{array}{l}0.67 \text { to } 1.08 \\
0.94 \text { to } 2.26 \\
0.88 \text { to } 1.59\end{array}$ \\
\hline Endoleak & $105(14.36 \%)$ & $864(16.35 \%)$ & 0.87 & 0.70 to 1.10 \\
\hline Type I (Proximal) & $22(3.01 \%)$ & $160(3.03 \%)$ & 0.91 & 0.57 to 1.46 \\
\hline Type I (Distal) & $15(2.05 \%)$ & $125(2.36 \%)$ & 0.88 & 0.51 to 1.53 \\
\hline Type II & $51(6.97 \%)$ & 466 (8.82\%) & 0.86 & 0.63 to 1.17 \\
\hline Type III & $12(1.64 \%)$ & $125(2.36 \%)$ & 0.66 & 0.36 to 1.22 \\
\hline Early death* & $29(4.37 \%)$ & $102(2.11 \%)$ & 1.67 & 1.71 to 2.61 \\
\hline Early conversion & $13(1.81 \%)$ & $62(1.20 \%)$ & 1.57 & 0.84 to 2.95 \\
\hline Early rupture & 0 & $1(0.02 \%)$ & - & - \\
\hline
\end{tabular}

Adjusted for patient age, sex, ASA classification, SVS risk factors, obesity, and unfitness for traditional open surgery or general anesthesia.

$\mathrm{Cl}$ : confidence interval.

* Significant difference between the diabetic and nondiabetic patients $(p<0.05)$.

glucose intolerance, insulin resistance, hyperinsulinemia, increased very-low-density lipoproteins and triglycerides, decreased highdensity lipoproteins, and hypertension. Diabetes has a considerable influence on the vascular condition of patients. Indeed, in our series, a greater proportion of the diabetic population was considered unfit for open surgery. They suffered more often from hypertension, hyperlipemia, and impaired cardiac and renal function than the nondiabetic study group.

\begin{tabular}{|c|c|c|}
\hline \multicolumn{3}{|c|}{$\begin{array}{c}\text { TABLE } 3 \\
\text { Cause of Early Mortality }\end{array}$} \\
\hline & $\begin{array}{c}\text { Diabetic } \\
\text { Patients } \\
n=731\end{array}$ & $\begin{array}{c}\text { Nondiabetic } \\
\text { Patients } \\
n=5286\end{array}$ \\
\hline Cardiac & $14(48.28 \%)$ & $29(28.43 \%)$ \\
\hline Pulmonary & $5(17.24 \%)$ & $12(11.76 \%)$ \\
\hline Renal & $1(3.45 \%)$ & $2(1.96 \%)$ \\
\hline Multiorgan failure & $1(3.45 \%)$ & $18(17.65 \%)$ \\
\hline Sepsis & $2(6.90 \%)$ & $13(12.75 \%)$ \\
\hline Other/unknown & $6(20.69 \%)$ & $26(25.49 \%)$ \\
\hline
\end{tabular}

However, limited information is available with regard to the effect of diabetes on EVAR. Rayan et al. ${ }^{11}$ investigated diabetes as a risk factor for patients undergoing open AAA repair who enrolled in the Vascular Surgery Registry. Proportionally higher postoperative

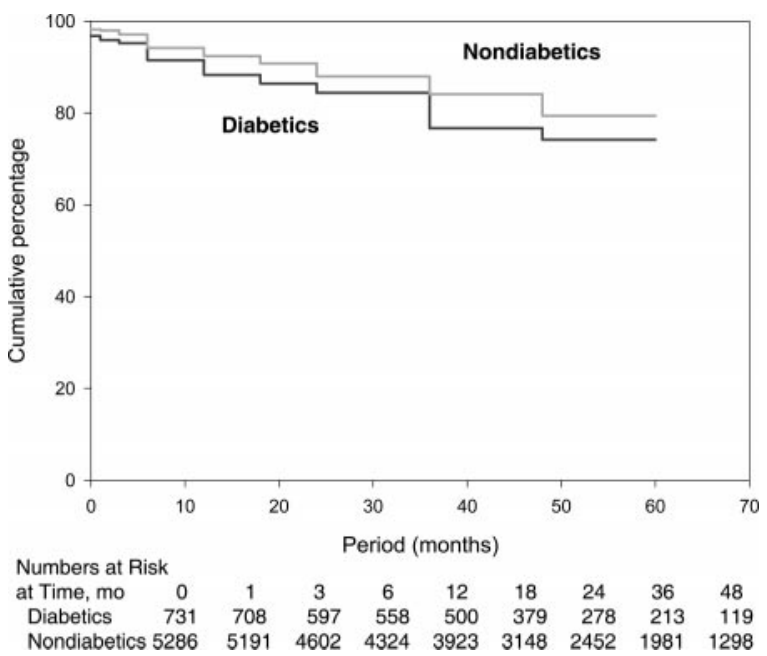

Figure $\triangleleft$ Life-table analysis of survival for diabetic versus nondiabetic EVAR patients. 
TABLE 4

Early Complications: Diet vs. Insulin-Controlled Type 2 Diabetics

\begin{tabular}{|c|c|c|c|c|}
\hline & $\begin{array}{c}\text { Diet-Controlled } \\
\quad n=505\end{array}$ & $\begin{array}{c}\text { Insulin- } \\
\text { Controlled } \\
n=205\end{array}$ & $\begin{array}{l}\text { Adjusted } \\
\text { Odds Ratio }\end{array}$ & $95 \% \mathrm{Cl}$ \\
\hline \multicolumn{5}{|l|}{ Intraoperative } \\
\hline Device-related & $46(9.13 \%)^{*}$ & $11(5.39 \%)$ & 0.57 & 0.29 to 1.12 \\
\hline Failed procedure & $12(2.38 \%)$ & $4(1.96 \%)$ & 0.82 & 0.26 to 2.57 \\
\hline Arterial & $23(4.56 \%)$ & $11(5.39 \%)$ & 1.19 & 0.57 to 2.49 \\
\hline Thrombus/emboli & $2(0.40 \%)$ & $1(0.49 \%)$ & & \\
\hline Occluded renal artery & $6(1.19 \%)^{*}$ & $2(0.98 \%)$ & 0.82 & 0.16 to 4.11 \\
\hline \multicolumn{5}{|l|}{ In-Hospital } \\
\hline Systemic & $60(11.90 \%)$ & $30(14.71 \%)$ & 1.28 & 0.80 to 2.05 \\
\hline Procedure/device-related & $21(4.17 \%)^{*}$ & $5(2.45 \%)$ & 0.58 & 0.21 to 1.55 \\
\hline Access/lower limb & $41(8.13 \%)$ & $19(9.31 \%)$ & 1.16 & 0.66 to 2.05 \\
\hline Endoleakt & $87(17.23 \%)$ & $17(8.29 \%) \ddagger$ & 0.43 & 0.25 to 0.75 \\
\hline Type I (Proximal)† & $20(3.96 \%)$ & $1(0.49 \%) \ddagger$ & 0.12 & 0.02 to 0.89 \\
\hline Type I (Distal) & $14(2.77 \%)$ & $1(0.49 \%)$ & 0.17 & 0.02 to 1.31 \\
\hline Type II & $40(7.92 \%)$ & $10(4.88 \%)$ & 0.60 & 0.29 to 1.21 \\
\hline Type III & $10(1.98 \%)$ & $2(0.98 \%)$ & 0.49 & 0.11 to 2.25 \\
\hline Early death & $22(4.36 \%)$ & $7(3.41 \%)$ & 0.78 & 0.33 to 1.85 \\
\hline
\end{tabular}

Adjusted for patient age, sex, ASA classification, SVS risk factors, obesity, and unfitness for traditional open surgery or general anesthesia.

$\mathrm{Cl}$ : confidence interval.

* Significant difference between the diet-controlled diabetic patients and the nondiabetic patients $(p<0.045)$.

† Significant difference between the diet and insulin-controlled subgroups $(p<0.015)$.

‡ Significant difference between the insulin-controlled diabetic patients and the nondiabetic patients $(p<0.035)$.

\begin{tabular}{|c|c|c|c|c|}
\hline \multicolumn{5}{|c|}{$\begin{array}{l}\text { TABLE } 5 \\
\text { Late Complications }\end{array}$} \\
\hline & $\begin{array}{c}\text { Diabetic } \\
\text { Patients } \\
n=731\end{array}$ & $\begin{array}{c}\text { Nondiabetic } \\
\text { Patients } \\
n=5286\end{array}$ & $\begin{array}{c}\text { Adjusted } \\
\text { Hazard } \\
\text { Rate }\end{array}$ & $95 \% \mathrm{Cl}$ \\
\hline Endoleak & $119(16.28 \%)$ & $953(18.03 \%)$ & 1.05 & 0.87 to 1.28 \\
\hline Type I (proximal) & $20(2.74 \%)$ & $157(2.97 \%)$ & 1.03 & 0.64 to 1.67 \\
\hline Type I (distal) & $27(3.69 \%)$ & $218(4.12 \%)$ & 1.09 & 0.72 to 1.63 \\
\hline Type II & $67(9.17 \%)$ & $563(10.65 \%)$ & 0.96 & 0.74 to 1.25 \\
\hline Type III & $28(3.83 \%)$ & $227(4.29 \%)$ & 1.19 & 0.80 to 1.78 \\
\hline Kinked stent-graft & $13(1.91 \%)$ & $183(3.46 \%)$ & 0.81 & 0.47 to 1.41 \\
\hline Stenosis/thrombosis & $38(5.20 \%)$ & $281(5.32 \%)$ & 1.08 & 0.76 to 1.53 \\
\hline Graft migration & $24(3.28 \%)$ & $275(5.20 \%)$ & 0.87 & 0.57 to 1.33 \\
\hline Secondary intervention & $71(9.71 \%)$ & $586(11.09 \%)$ & 1.07 & 0.83 to 1.38 \\
\hline Late death & $67(9.16 \%)$ & $452(8.55 \%)$ & 1.15 & 0.88 to 1.50 \\
\hline Late conversion & $11(1.50 \%)$ & $118(2.23 \%)$ & 1.02 & 0.54 to 1.91 \\
\hline Late rupture & $2(0.27 \%)$ & $43(0.81 \%)$ & 0.44 & 0.10 to 1.84 \\
\hline
\end{tabular}

Adjusted for patient age, sex, ASA classification, SVS risk factors, obesity, and unfitness for traditional open surgery or general anesthesia.

$\mathrm{Cl}$ : confidence interval. 
TABLE 6

Late Complications: Diet vs. Insulin-Controlled Type 2 Diabetes

\begin{tabular}{lcccc}
\hline & $\begin{array}{c}\text { Diet- } \\
\text { Controlled } \\
\mathrm{n}=505\end{array}$ & $\begin{array}{c}\text { Insulin- } \\
\text { Controlled } \\
\mathrm{n}=205\end{array}$ & $\begin{array}{c}\text { Adjusted } \\
\text { Hazard Rate }\end{array}$ & $95 \% \mathrm{Cl}$ \\
\hline Endoleak* & $99(19.60 \%)$ & $16(7.8 \%) \dagger$ & 0.35 & 0.20 to 0.61 \\
$\quad$ Type I (proximal) & $14(2.77 \%)$ & $4(1.95 \%)$ & 0.71 & 0.23 to 2.21 \\
Type I (distal) & $23(4.55 \%)$ & $3(1.46 \%)$ & 0.32 & 0.09 to 1.07 \\
Type II* & $55(10.89 \%)$ & $10(4.88 \%) \dagger$ & 0.43 & 0.21 to 0.86 \\
$\quad$ Type III & $23(4.55 \%)$ & $5(2.44 \%)$ & 0.54 & 0.20 to 1.43 \\
Kinked stent-graft & $12(2.38 \%)$ & $1(0.49 \%)$ & 0.21 & 0.03 to 1.60 \\
Stenosis/thrombosis & $27(5.35 \%)$ & $11(5.37 \%)$ & 1.03 & 0.50 to 2.13 \\
Graft migration & $21(4.16 \%)$ & $3(1.46 \%) \dagger$ & 0.35 & 0.10 to 1.19 \\
Secondary intervention* & $62(12.28 \%)$ & $8(3.9 \%) \dagger$ & 0.29 & 0.14 to 0.63 \\
Late death & $46(9.11 \%)$ & $20(9.76 \%)$ & 1.08 & 0.62 to 1.87 \\
Late conversion & $10(1.98 \%)$ & $1(0.49 \%)$ & 0.24 & 0.03 to 1.91 \\
Late rupture & $1(0.20 \%)$ & $1(0.49 \%)$ & 2.47 & 0.15 to 39.69 \\
$\bullet$ - &
\end{tabular}

Adjusted for patient age, sex, ASA classification, SVS risk factors, obesity, and unfitness for traditional open surgery or general anesthesia. $\mathrm{Cl}$ : confident interval.

* Significant difference between the diet and insulin-controlled subgroups $(p<0.015)$. † Significant difference between insulin-controlled diabetic patients and nondiabetic patients $(p<0.025)$.

mortality was noticed in the diabetic population. However, long-term cumulative survival was identical for diabetic versus nondiabetic patients, which we found when analyzing the correlation between diabetes and endovascular AAA repair.

In our investigation of the relationship between diabetes and EVAR, patients with diabetes more often experienced device-related complications and arterial sequelae, such as occlusion of the renal artery. The most striking finding was the significantly higher 30-day mortality rate $(4 \%)$ in the diabetic group, which was caused primarily by cardiac insufficiency. However, this higher early mortality rate was still in the $0 \%$ to $7 \%$ range reported by other recent studies analyzing EVAR. ${ }^{1,5,12-14}$ de Virgilio et al. ${ }^{15}$ compared cardiac morbidity and mortality between conventional and endovascular AAA repair, but in their study, diabetes was not a predictive criterion for an adverse cardiac event $(p=0.07)$.

In type 2 diabetes, insulin treatment is used when diet, exercise, and oral agents are unable to establish adequate glycemic control. The United Kingdom Prospective Diabetes Study showed that improved glycemic condition in type 2 diabetes reduced vascular and all diabetes-related complications. ${ }^{16,17}$ Some authors have demonstrated a relationship between the duration of diabetes and the incidence of vascular complications, although the issue is disputed by several other investigators. ${ }^{18-25}$ Type 2 diabetes mellitus was frequently missed at diagnosis because hyperglycemia frequently was not severe enough to provoke characteristic symptoms of diabetes. Nevertheless, in this stage, patients are at increased risk of developing macrovascular and microvascular complications. ${ }^{26,27}$ The fact that elevated blood glucose levels may have been present for several months or even years before the diagnosis of type 2 diabetes is made complicates the analyses. Hence, the actual duration of type 2 diabetes cannot easily be estimated.

Compared to diet-controlled (oral hypoglycemic) or nondiabetic patients in our study, insulin-controlled type 2 diabetics had a significantly lower rate of endoleaks, which resulted in fewer secondary interventions. The lower incidence of endoleak in this patient group may be explained by the impact of diabetes on blood vessels. Diabetes affects the endothelial lining of arteries, causing them to become clogged with plaque, so the aortic 
side branches, including the lumbar, inferior mesenteric, internal iliac, and renal arteries, become less elastic and more occlusive. In addition, medication to help keep the blood glucose levels within a safe range or to control diabetes-related complications, such as high blood pressure or nephropathy (e.g., angiotensin-converting enzyme inhibitors or angiotensin II receptor blockers), may influence the arterial condition and endoleak development. 9,28

Riambeau et al. ${ }^{29}$ analyzed the association between comorbidity and mortality after EVAR in patients considered unfit for open surgery. The survival curves in patients with poor medical condition were significantly worse than in those with a good medical status. However, the presence of co-existing diseases in patients unfit for open surgery did not affect the mortality rate. In our study population, the survival curves of diabetic and nondiabetic patients demonstrated similar cumulative survival after 4 years.

EUROSTAR, like any voluntary registry, has its advantages and disadvantages. The main advantages are the ability to gather a large amount of data on a diverse patient population in a relatively short period of time, address upcoming questions, evaluate longterm effectiveness, and include new devices or improvements. Disadvantages are a lack of randomization and double-blinding, a large interobserver variation, and less accurate and complete data. Nevertheless, a registry population normally is a good reflection of common day clinical practice.

\section{Conclusions}

Patients with diabetes had a significantly higher 30-day mortality rate then patients without diabetes. After a lower initial success rate, long-term survival was similar in both study groups. More assessment is needed to evaluate the effect of diabetes on EVAR outcome.

\section{APPENDIX}

EUROSTAR centers that contributed to this study:
Austria: University Hospital, Vienna.

Belgium: ASZ and Onze Lieve Vrouwe Hospital, Aalst; AZ Middelheim, St. Vincentius Hospital, UIA, Monica Hospital/OLV/Eeuwfeestkliniek, and St. Augustinus Hospital, Antwerpen; AZ St. Lucas/St. Jozef, Assebroek; Hospital Princesse Paola, Aye; Imelda Hospital, Bonheiden; AZ Klina, Brasschaat; AZ St. Jan AV, Brugge; Hospital Erasme, Academic Hospital VUB, Clinique de l'Europe St. Michel, CHU Brugmann, and University Hospital St. Luc, Brussels; CHU, Charleroi; AZ St. Blasius, Dendermonde; AZ St. Maarten, Duffel; AZ St. Dimpna, Geel; St. Jan Hospital, AZ St. Lucas, and University Hospital, Genk; St. Joseph Hospital, Gilly; Virga Jesse Hospital, Hasselt; St. Elisabeth, Herenthals; CAZ St. Franciskus Hospital, Heusden-Zolder; AZ Groenige, Kortrijk; University Hospital and Heilig Hart, Leuven; Notre-Dame des Bruyeres, Liège-Chenee; Maria Hospital, Lommel; OLV Hospital, Mechelen; CHM CNDT, Moucron; CHRN, Namur; AZ Heilige Familie, Reet; Stedelijk Hospital and HHR Hart Hospital, Roeselare; St. Trudo Hospital, St. Truiden; St. Josef Hospital, Turnhout; St. Augustinus Hospital, Veurne; St, Josef Hospital, Vilvoorde.

Denmark: Rigshospitalet, Copenhagen; University Hospital, Odense.

France: Hospital Notre Dame, Draguignan; Clinique Mutaliste des Eaux Claires, Grenoble; Hospital for Cardiology, Lille; Hospital Jeanne d'Arc and Hospital E Herriot, Lyon; Polyclinic d'Essey, Nancy; Hospital de la Defense, Nanterre; Hospital Henri Mondor and Hospital Broussais, Paris; CHU Hospital North, St. Etienne; Institut Arnauld Tzanck, St. Laurant du Var; Hospital Sarrus Teinturier and Hospital de Rangueil, Toulouse.

Germany: Surgical University Clinic, Bonn; Augusta Hospital, Düsseldorf; Städtischen Kliniken and Sankt Katharinen, Frankfurt; University Hospital, Freiburg; Altona General Hospital, Hamburg; Henriettenstiftung, Hannover; Klinikum Kempten; Bundeswehrzentral, Koblenz; Park-Krankenhaus, Leipzig; University Hospital, Mainz; Philipps-University, Marburg; Kliniken Rechts der Isar, München; Pius Hospital, Oldenburg; University Hospital, UIm.

Greece: University Medical School, Athens. Ireland: St. James Hospital, Dublin. 
Israel: Sheba Medical Centre, Tel Aviv.

Italy: Policlinico Monteluce, Perugia; Ospedale S Giovanni, Rome.

Luxembourg: Centre Hospitalier, Luxembourg.

Monaco: Centre Cardio-Thoracique, Monaco.

The Netherlands: Medical Centre, Alkmaar; Academic Medical Centre, VU, and Onze Lieve Vrouwe Gasthuis, Amsterdam; Gelre Hospital, Apeldoorn; Rijnstate, Arnhem; Reinier de Graaf Group, Delft; Medical Centre Haaglanden Westeinde and Leijenburg Hospital, The Hague; Albert Schweitzer Hospital, Dordrecht; Catharina Hospital, Eindhoven; Medisch Spectrum Twente, Enschede; St. Anna Hospital, Geldrop; Academic Hospital and Martini Hospital, Groningen; Academic Hospital, Maastricht; St. Antonius Hospital, Nieuwegein; CWZ Hospital and Academic Hospital, Nijmegen; St. Clara Hospital, Dijkzicht Hospital, and Franciscus Gasthuis, Rotterdam; Elisabeth Hospital and Tweesteden Hospital, Tilburg; University Medical Centre, Utrecht; St. Josef Hospital, Veldhoven; Isala Clinics Sophia, Zwolle.

Norway: Aker University Hospital and UIleval Hospital, Oslo; University Hospital, Trondheim.

Poland: L'Academie de Medicine, Lublin; Medical University, MSWiA Hospital, and Central Military Hospital, Warsaw.

Spain: University Hospital, Ciutat Sanitaria i Universitaria de Bellvitge, and Hospital de la Santa Creu i Sant Pau, Barcelona; Hospital de Gipuzkoa, Donostia San Sebastian; Hospital Juan Canalejo and Hospital Santa Teresa, La Coruña; Hospital de Leon, Hospital Xeral Lugo, University Hospital de la Princesa, Hospital Ramon y Cajal, Fundacion Jimenez Diaz, and University Hospital of Getafe, Madrid; University Hospital of Navarra, Pamplona; Hospital Clinico, Valladolid.

Sweden: University Hospital, Lund; Medical Centre, Örebro.

Switzerland: Clinic for Cardiovascular Surgery, Bern; Gefässzentrum, Zürich.

Turkey: Memorial Hospital and University Hospital, Istanbul.

United Kingdom: Royal Hospital, Bournemouth; Royal Infirmary, Bristol; Countess of Chester Hospital, Chester; Gartnavel Hospital,
Glasgow; Royal Infirmary, Hull; Royal University Hospital, Liverpool; St. Mary's Hospital, London; Withington Hospital, Manchester; Freeman Hospital, New Castle-Upon-Tyne.

\section{REFERENCES}

1. Matsumura JS, Brewster DC, Makaroun MS, et al. A multicenter controlled clinical trial of open versus endovascular treatment of abdominal aortic aneurysm. J Vasc Surg. 2003;37:262-271.

2. Becquemin JP, Bourriez $A$, d'Audiffret $A$, et al. Mid-term results of endovascular versus open repair of abdominal aortic aneurysm in patients anatomically suitable for endovascular repair. Eur J Vasc Endovasc Surg. 2000;19:656661.

3. Cuypers P, Nevelsteen A, Buth J, et al. Complications in the endovascular repair of abdominal aortic aneurysms: a risk factor analysis. Eur $J$ Vasc Endovasc Surg. 1999;18:245-252.

4. Cuypers P, Buth J, Harris PL, et al. Realistic expectations for patients with stent-graft treatment of abdominal aortic aneurysms. Results of a European multicenter registry. Eur J Vasc Endovasc Surg. 1999;17:507-516.

5. Buth J, Laheij RJ, on behalf of the EUROSTAR Collaborators. Early complications and endoleaks after endovascular abdominal aortic aneurysm repair: report of a multicenter study. $J$ Vasc Surg. 2000;31:134-146.

6. Adriaensen ME, Bosch JL, Halpern EF, et al. Elective endovascular versus open surgical repair of abdominal aortic aneurysms: a systemic review of short-term results. Radiology. 2002; 224:739-747.

7. Greenhalgh RM, Brown LC, Kwong GP, et al. Comparison of endovascular aneurysm repair with open repair in patients with abdominal aortic aneurysm (EVAR trial 1), 30-day operative mortality results: randomised controlled trial. Lancet. 2004;364:843-848.

8. Prinssen M, Verhoeven ELG, Buth J, et al. A randomized trial comparing conventional and endovascular repair of abdominal aortic aneurysms. N Engl J Med. 2004;351:1607-1618.

9. Khamaisi M, Wexler ID, Skrha J, et al. Cardiovascular disease in type 2 diabetics: epidemiology, risk factors and therapeutic modalities. Isr Med Assoc J. 2003;5:801-806.

10. Chaikof EL, Blankensteijn JD, Harris PL, et al. Reporting standards for endovascular aortic aneurysm repair. J Vasc Surg. 2002;35:10481060.

11. Rayan SS, Hamdan AD, Campbell DR, et al. Is diabetes a risk factor for patients undergoing 
open abdominal aortic aneurysm repair? Vasc Endovascular Surg. 2002;36:33-40.

12. Bush RL, Lumsden AB, Dodson TF, et al. Midterm results after endovascular repair of the abdominal aortic aneurysm. J Vasc Surg. 2001; 33:S70-76.

13. Harris $P L$, Vallabhaneni $S R$, Desgranges $P$, et al. Incidence and risk factors of late rupture, conversion, and death after endovascular repair of infrarenal aortic aneurysms: the EUROSTAR experience. J Vasc Surg. 2000;32:739-749.

14. Criado FJ, Fairman RM, Becker GJ. Talent LPS AAA stent graft: results of a pivotal clinical trial. J Vasc Surg. 2003;37:709-715.

15. de Virgilio C, Bui H, Donayre C, et al. Endovascular vs open abdominal aortic aneurysm repair. A comparison of cardiac morbidity and mortality. Arch Surg. 1999;134:947-951.

16. Laakso M. Hyperglycemia as a risk factor for cardiovascular disease in type 2 diabetes. Prim Care. 1999;26:829-839.

17. Nicollerat JA. Implications of the United Kingdom Prospective Diabetes Study (UKPDS) results on patient management. Diabetes Educ. 2000;26Suppl:8-10.

18. McCance DR, Hanson RL, Charles MA, et al. Comparison of tests for glycated haemoglobin and fasting and two hour plasma glucose concentrations as diagnostic methods for diabetes. BMJ. 1994;308:1323-1328.

19. Engelgau MM, Thompson TJ, Herman WH, et al. Comparison of fasting and 2-hour glucose and $\mathrm{HbA}_{1 \mathrm{c}}$ levels for diagnosing diabetes: diagnostic criteria and performance revisited. Diabetes Care. 1997;20:785-791.
20. Charles MA, Balkau B, Vauzelle-Kervroedan F, et al. Revision of diagnostic criteria for diabetes [Letter]. Lancet. 1996;348:1657-1658.

21. Alberti KG. The clinical implications of impaired glucose tolerance. Diabet Med. 1996;13: 927-937.

22. McCance DR, Hanson RL, Pettitt DJ, et al. Diagnosing diabetes mellitus-do we need new criteria? Diabetologia. 1997;40:247-255.

23. Jarrett RJ. Epidemiology and public health aspects of non-insulin-dependent diabetes mellitus. Epidemiol Rev. 1989;11:151-171.

24. Nathan DM, Singer DE, Godine JE, et al. Noninsulin-dependent diabetes in older patientscomplications and risk factors. Am J Med. 1986;81:837-842.

25. Keen H, Jarrett RJ, Fuller JH, et al. Hyperglycemia and arterial disease. Diabetes. 1981; 30(suppl 2):49-53.

26. Mooy JM, Grootenhuis PA, de Vries $\mathrm{H}$, et al. Prevalence and determinants of glucose intolerance in a Dutch population. The Hoorn Study. Diabetes Care. 1995;18:1270-1273.

27. Harris MI. Undiagnosed NIDDM; clinical and public health issues. Diabetes Care. 1993;16: 642-652.

28. De La Sierra A, Ruilope LM. Treatment of hypertension in diabetes mellitus. Curr Hypertens Rep. 2000;2:335-342.

29. Riambau V, Laheij RJF, García-Madrid C, et al. The association between co-morbidity and mortality after abdominal aortic aneurysm endografting in patients ineligible for elective open surgery. Eur J Vasc Endovasc Surg. 2001; 22:265-270. 